\title{
Review Article \\ Myeloid-Derived Suppressor Cells and Therapeutic Strategies in Cancer
}

\author{
Hiroshi Katoh and Masahiko Watanabe \\ Department of Surgery, Kitasato University School of Medicine, 1-15-1 Kitasato, Minami-ku, Sagamihara, Kanagawa 252-0374, Japan \\ Correspondence should be addressed to Hiroshi Katoh; hiroshik@med.kitasato-u.ac.jp
}

Received 26 January 2015; Accepted 23 March 2015

Academic Editor: Analía Trevani

Copyright ( $) 2015$ H. Katoh and M. Watanabe. This is an open access article distributed under the Creative Commons Attribution License, which permits unrestricted use, distribution, and reproduction in any medium, provided the original work is properly cited.

\begin{abstract}
Development of solid cancer depends on escape from host immunosurveillance. Various types of immune cells contribute to tumorinduced immune suppression, including tumor associated macrophages, regulatory T cells, type 2 NKT cells, and myeloid-derived suppressor cells (MDSCs). Growing body of evidences shows that MDSCs play pivotal roles among these immunosuppressive cells in multiple steps of cancer progression. MDSCs are immature myeloid cells that arise from myeloid progenitor cells and comprise a heterogeneous immune cell population. MDSCs are characterized by the ability to suppress both adaptive and innate immunities mainly through direct inhibition of the cytotoxic functions of T cells and NK cells. In clinical settings, the number of circulating MDSCs is associated with clinical stages and response to treatment in several cancers. Moreover, MDSCs are reported to contribute to chemoresistant phenotype. Collectively, targeting MDSCs could potentially provide a rationale for novel treatment strategies in cancer. This review summarizes recent understandings of MDSCs in cancer and discusses promissing clinical approaches in cancer patients.
\end{abstract}

\section{Introduction}

Chronic inflammatory stimuli are one of key risk factors for initiating and developing cancer. Indeed, the common pathological feature of chronic inflammation (e.g., chronic colitis) and solid cancer involves a massive infiltration of immune cells into the sites. The pathological changes in solid cancers include recruitment and modifying of various types of dysregulated immune cells and endothelial cells to form a tumor microenvironment [1]. A variety of chemokines and cytokines are produced by cancer cells and surrounding stromal cells and recruit leukocytes from the circulation to local sites according to their chemokine gradient. Cancerassociated fibroblasts (CAFs) constitute majority of the tumor stromal cells and play a critical role in tumor development [2]. Most of CAFs are also recruited from bone marrow via chemokine signaling as well as immune cells [3]. Cancer cells regulate and modify these immune cells to escape from host side immune system. A growing body of evidence supports that cancer initiation and progression essentially depend on escape from host immunosurveillance. Immune evasion involves a shift of immune responses, including imbalance in $\mathrm{Th} 1 / \mathrm{Th} 2$ responses and enhancement of immunosuppressive cells such as myeloid-derived suppressor cells (MDSCs), regulatory T cells, M2 macrophages (tumorassociated macrophages), and type 2 NKT cells. MDSCs are a heterogeneous population of immune cells characterized by the ability to suppress cytotoxic functions of $\mathrm{T}$ cells and NK cells [4]. MDSCs originate from myeloid progenitor cells and are thought to be immature cells that do not differentiate into granulocytes, macrophages, or dendritic cells (DCs). Pathological conditions such as infection, trauma, autoimmune diseases, and cancer trigger expansion of MDSCs in bone marrow and spleen. MDSCs then accumulate in the peripheral blood, tumor, lymphoid organs, and parenchymal organs. In the past decade, MDSCs have been thought essential especially in solid cancers and one of key drivers of not only cancer-associated immune evasion but also tumor progression and metastasis by establishing tumor microenvironment [5]. Indeed, the number of circulating MDSCs in the peripheral blood correlates well with clinical cancer stage and metastatic tumor burden in patients $[6,7]$. MDSCs 
also play a key role in gaining chemoresistant phenotype in cancer $[8,9]$. Therefore, targeting MDSCs would be promising treatment option for patient with cancer. This review summarizes and discusses the recruitment mechanisms and immunosuppressive functions of MDSCs and the potential strategies to target cancer-associated MDSCs.

\section{Phenotypes of MDSCs in Cancer}

MDSCs are composed of heterogeneous immature myeloid cells that arise from bone marrow progenitor cells, at different stages of differentiation from early myeloid cells to more differentiated macrophages, granulocytes, or dendritic cells. MDSCs accumulate in tumor tissues and in the peripheral lymphoid organs. MDSCs are also found to

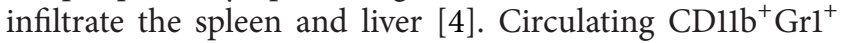
cells are arrested and accumulate in the splenic marginal zones and migrate to the red pulp and proliferate $[10$, 11], suggesting that $\mathrm{CD} 1 \mathrm{~b}^{+} \mathrm{Grl}^{+}$cells in peripheral blood may represent both proliferated MDSCs and precursors for MDSCs. In mice, MDSCs are broadly characterized

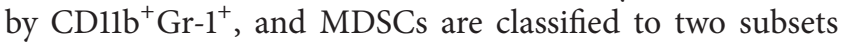
as either granulocytic (polymorphonuclear) MDSCs (GMDSCs) or mononuclear MDSCs (M-MDSCs) (Figure 1). GMDSCs are defined as $\mathrm{CD}_{11 b^{+}} \mathrm{Ly}_{6 \mathrm{G}^{\mathrm{hi}}} \mathrm{Ly}_{6 \mathrm{C}^{\mathrm{lo}}}$ and M-MDSCs

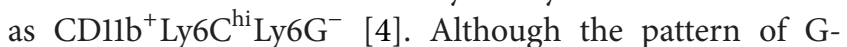
MDSC and M-MDSC subsets differs between tumors and organs, over $80 \%$ of MDSCs are G-MDSCs, whereas less than $10 \%$ of MDSCs are M-MDSCs in most of experimental models [12-14]. However, substantial neutrophils also express both CD11b and Ly6G, causing difficulty to discriminate GMDSCs from neutrophils. In addition to reactive oxygen species (ROS) and arginase 1 (Arg1), M-CSFR and CD244 have been proposed as phenotypes of G-MDSCs [15].

In human, phenotypes of human MDSCs are yet to be clarified and much more complicated with phenotypic diversity and heterogeneity. Circulating $\mathrm{CD}^{+} 3^{+}$cells, $\mathrm{CD}_{3}{ }^{+} \mathrm{HLA}-\mathrm{DR}{ }^{-}$, or $\mathrm{CD}_{3}{ }^{+} \mathrm{HLA}_{-} \mathrm{DR}^{-} \mathrm{Lin}^{-}$are described to be MDSCs in patients with renal cell cancer, colorectal cancer, or hepatocellular carcinoma, respectively [16-18]. $\mathrm{CD}_{11 b^{+}} \mathrm{CD}_{3}{ }^{+}$cells are reported as MDSCs in peripheral blood of patients with non-small cell lung cancer [19]. $\mathrm{Yu}$ et al. suggested $\mathrm{CD} 45^{+} \mathrm{CD} 13^{+} \mathrm{CD} 33^{+} \mathrm{CD} 14^{-} \mathrm{CD} 15^{-}$ MDSCs in tumors and peripheral blood of breast cancer patients [20]. In general, human MDSCs are defined as CD11b-positive, CD33-positive, HLA-DR-negative or low, and lineage markers (Lin) (CD3, CD14, CD19, CD56)- negative [11]. Zhang et al. described circulating

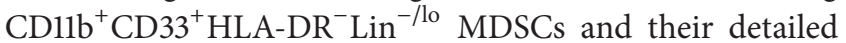
profiles as $\mathrm{CD} 13^{\text {hi }} \mathrm{CD} 39^{\text {hi }} \mathrm{CD} 115^{\text {lo }} \mathrm{CD} 117^{\text {lo }} \mathrm{CD} 124^{\text {lo }} \mathrm{PD}$ $\mathrm{L} 1{ }^{\text {lo }} \mathrm{CD} 14^{-} \mathrm{CD} 15^{-} \mathrm{CD} 66 \mathrm{~b}^{-}$in patients with colorectal cancer [21]. Similarly to mice, human MDSCs can be phenotypically classified as granulocytic and monocytic population (Figure 1). G-MDSCs express a granulocytic marker CD15 or CD66b in addition to CD11b and CD33 in head and neck cancer, non-small cell lung cancer, pancreas cancer, bladder cancer, renal cell cancer, and breast cancer [22-27]. On the other hand, human M-MDSCs have been described as $\mathrm{CD}_{1}{ }^{+} \mathrm{HLA}-\mathrm{DR}^{-}\left(\mathrm{CD} 33^{+} \mathrm{Lin}^{-}\right)$in hepatocellular carcinoma, metastatic prostate cancer, renal cell cancer, and malignant melanoma [28-31]. M-MDSCs

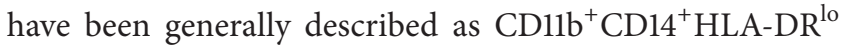
or $\mathrm{CD}_{11} \mathrm{~b}^{+} \mathrm{CD} 14^{-} \mathrm{CD} 15^{-}$(or $\mathrm{CD}^{-} 6 \mathrm{~b}^{-}$) [22-25]. VasquezDunddel et al. defined M-MDSCs in tumors, draining lymph

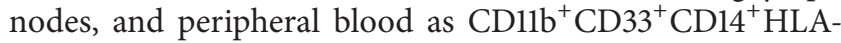
$\mathrm{DR}^{-/ \mathrm{lo}} \mathrm{CD} 4^{+} \mathrm{Arg}^{+} \mathrm{ROS}^{+}$in head and neck squamous cancer [32]. Numerous combinations of these markers have been reported in human solid cancers [33].

\section{Mechanism of MDSC-Mediated Immunosuppression}

Immunosuppression of cytotoxic $\mathrm{T}$ cells and $\mathrm{NK}$ cells is a hallmark of MDSCs. Direct cell-to-cell contact is required for such immunosuppressive activities of MDSCs [4]. Numerous preclinical studies have showed the mechanisms of MDSCmediated immune suppression. MDSCs suppressive activity against $\mathrm{T}$ cells is associated with $\mathrm{L}$-arginine metabolism. Larginine is a substrate for inducible nitric oxide synthase (iNOS) and arginase 1 (Arg1). Arg1 and reactive oxygen species (ROS) are upregulated in activated G-MDSCs, while Argl and iNOS are highly expressed in activated M-MDSCs. The upregulation of either Arg1 or iNOS results in Larginine shortage, leading to consequent inhibition of $\mathrm{T}$ cell proliferation through multiple mechanisms such as reduction of CD3 $\zeta$-chain expression and IFN- $\gamma /$ IL- 2 secretion by $\mathrm{T}$ cells $[4,13,34,35]$. High levels of ROS in G-MDSCs can induce nitrosylation of the $\mathrm{T}$ cell receptor (TCR) during direct cell-to-cell communication, which contributes to the inhibition of antigen-specific $\mathrm{T}$ cell activation [13, 36, 37]. ROS production by G-MDSCs is known to be induced by several tumor-derived factors such as TGF $\beta$, IL-6, IL-10, and GM-CSF [4]. The suppressive function of G-MDSCs depends on Arg1 and ROS, whereas that of M-MDSCs requires signal transducer and activator of transcription 1 (STAT1) and iNOS [38]. In activated G-MDSCs, STAT3 is highly activated, which results in increased expression levels of ROS via upregulation of NADPH oxidase (NOX2) but not NO production. On the other hand, STAT1 and iNOS are highly upregulated in MMDSCs, resulting in increased levels of NO but not ROS production [4]. In addition, STAT6 signaling pathway is involved in upregulation of Arg1 and TGF- $\beta$ through activation of IL-4 and IL-13, leading to immunosuppressive activity [39, 40]. However, the immunosuppressive mechanisms overlap between G-MDSCs and M-MDSCs in human cancers. iNOS is also upregulated in G-MDSCs in a variety of human cancer $[24,41,42]$. CD14 ${ }^{+} \mathrm{HLA}_{-D R^{-/ \mathrm{lo}}}$ M-MDSCs express NADPH oxidase component gp91 (phox) and produce high level of ROS in human non-small cell lung cancer [43]. These MMDSCs inhibit T cell proliferation and IFN- $\gamma$ secretion in a cell-contact-dependent manner.

Another mechanism of immunosuppressive activity of MDSCs against $\mathrm{T}$ cells is cysteine deprivation. Cysteine is essential for $\mathrm{T}$ cell activation but cannot be synthesized by $\mathrm{T}$ cells. Antigen-presenting dendritic cells and macrophages can deliver cysteine by converting methionine and cystine to 


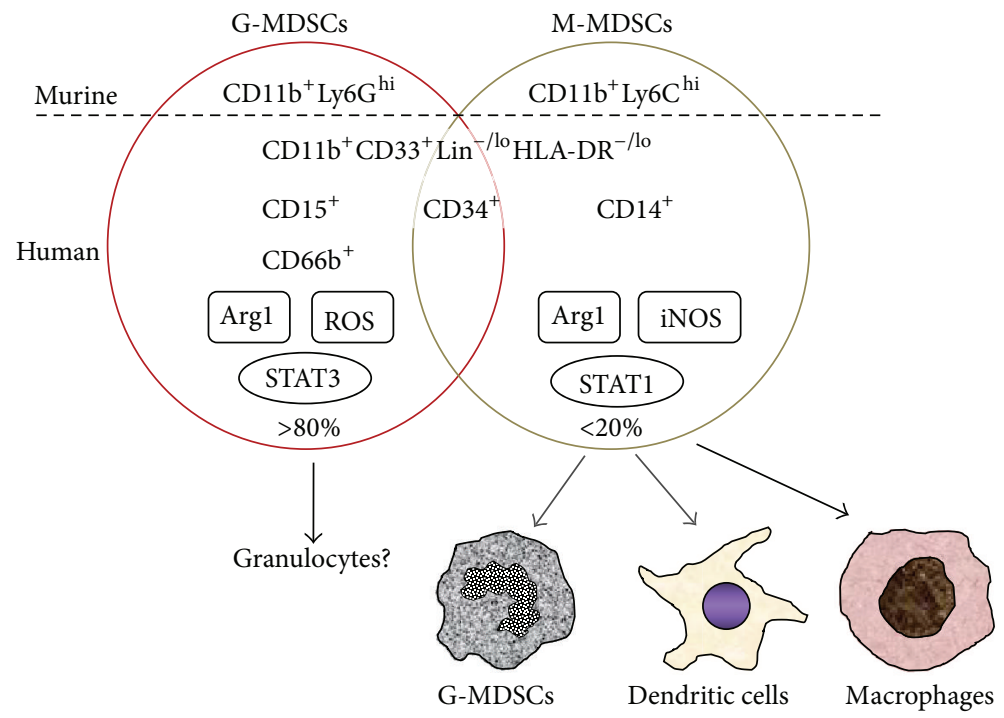

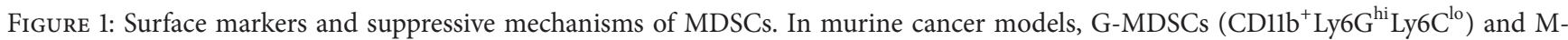
MDSCs (CD11b ${ }^{+}$Ly6 $\mathrm{C}^{\text {hi }}{\text { Ly } 6 G^{-}}^{-}$can be discriminated by the cell surface markers. However, identifying human MDSCs is still challenging because of their phenotypic heterogeneity and the absence of cognate surface markers in mice. Generally, human MDSCs can be defined as $\mathrm{CD}_{11 \mathrm{~b}}{ }^{+} \mathrm{CD} 33^{+} \mathrm{Lin}^{-/ 10} \mathrm{HLA}-\mathrm{DR}^{-/ 10}$ and further divided to $\mathrm{CD}^{+} 5^{+}$or $\mathrm{CD}_{6} 6 \mathrm{~b}^{+} \mathrm{G}-\mathrm{MDSC}$ and $\mathrm{CD} 14^{+} \mathrm{M}-\mathrm{MDSC}$. A substantial population shows both CD15 (or CD66b) and CD14 negative, suggesting that G-MDSCs and M-MDSCs are not completely distinct population. M-MDSCs can differentiate mature dendritic cells and macrophages or putatively G-MDSCs.

cysteine [44]. MDSCs also import extracellular cystine for converting it to cysteine but they do not export cysteine, leading to lack of cystine for dendritic cells and macrophage [45]. Recently, another subset of MDSCs, cancer-induced fibrocytes, is proposed. This novel subset of MDSCs shows phenotypic and functional characters of fibrocytes but mediates immune suppression by inhibiting $\mathrm{T}$ cell proliferation via indoleamine oxidase (IDO) in human metastatic pediatric sarcomas [46].

MDSCs can suppress the cytotoxic activity of NK cells and their IFN- $\gamma$ production [47]. CD14 ${ }^{+} \mathrm{HLA}-\mathrm{DR}^{-/ \mathrm{lo}} \mathrm{M}-$ MDSCs inhibit NK cell cytotoxicity and cytokine secretion in a cell-contact-dependent manner in human hepatocellular carcinoma [48]. The inhibition of NK cells is independent of arginase activity. On the other hand, MDSC-mediated immunosuppressive activities against NK cells are mainly dependent on the NKp30 on NK cells. Furthermore, MDSCs can skew macrophage-derived cytokine profiles from type 1 to type 2 putatively through Toll-like receptor 4 signaling pathway [49]. Indeed, increased MDSC levels in peripheral blood and tumor are closely associated with the infiltration of $\mathrm{CD}_{163}{ }^{+} \mathrm{M} 2$ macrophages in human esophageal cancer [50].

\section{Expansion and Trafficking of MDSCs}

Although mechanisms of induction and trafficking MDSCs are still elusive, multiple tumor-derived factors are suggested in preclinical models and cancer patients. These tumorderived factors include granulocyte-macrophage colonystimulating factor (GM-CSF), granulocyte colony-stimulating factor (G-SCF), macrophage colony-stimulating factor
(M-CSF), IL-1 $\beta$, IL-6, VEGF, IL-13, IL-10, prostaglandin $\mathrm{E}_{2}$ $\left(\mathrm{PGE}_{2}\right)$, TNF, bombina variegate peptide 8 (Bv8, also known as prokineticin 2 or Prok2), and stem cell factor (SCF) [5161]. Most of these tumor-derived factors activate signaling pathways which involve STAT3 or Janus kinase (JAK) in myeloid precursor cells [62]. Among these factors, GM-CSF and IL-6 may be most powerful in inducing MDSCs from bone marrow hematopoietic progenitors [63]. In addition to bone marrow, spleen is another source of MDSCs. Indeed, GM-CSF induces the $\mathrm{KIT}^{+}$MDSC precursors in spleen of tumor-bearing mice [64]. GM-CSF is also required for recruitment of MDSCs to the tumor microenvironment $[64,65]$. The STAT3 activation in myeloid precursor cells enhances MDSC proliferation and expansion in bone marrow and also promotes the production of calcium binding proteins S100A8 and S100A9 which form heterodimers and inhibit differentiation to dendritic cells, contributing expansion and accumulation of MDSCs [66]. S100A8/A9 bind to cell surface glycoprotein receptors on MDSCs and promote MDSC activation and migration through the NF$\kappa \mathrm{B}$ signaling pathway. MDSCs also synthesize and secrete S100A8/A9, resulting in an autocrine feedback loop that sustains accumulation of MDSCs [67]. Bv8 mobilizes immature myeloid cells from hematopoietic progenitor cells, and anti-Bv8 treatment decreases mobilization of $\mathrm{CD}_{11 b}{ }^{+} \mathrm{Gr}^{+}$ cells from bone marrow [61]. Tumor-derived $\mathrm{PGE}_{2}$ promotes differentiation of $\mathrm{CD} 1 \mathrm{~b}^{+} \mathrm{Grl}^{+}$cells from bone marrow stem cells through EP2 signaling [59]. PGE 2 stimulates MDSCs to produce high levels of Argl and iNOS in tumor and spleen through EP4 signaling pathway, leading to $\mathrm{T}$ cell suppressive functions $[35,68]$. In human ovarian cancer, 
positive feedback loop between $\mathrm{PGE}_{2}$ and cyclooxygenase2 (COX-2) facilitates the differentiation of human $\mathrm{CDla}^{+}$

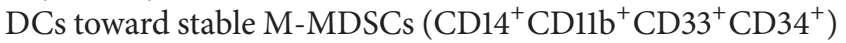
[57]. CCAAT-enhancer-binding protein $\beta(\mathrm{C} / \mathrm{EBP} \beta)$ also contributes to MDSCs expansion and activation of the immunoregulatory activity of MDSCs [69]. Additionally, human hepatic stellate cells (HSCs) may have capacity to transform monocytes in peripheral blood into MDSCs in a CD44-dependent manner [70].

As aforementioned, GM-CSF promotes migration of MDSCs to tumor. Several chemokine systems have been suggested to be involved in recruitment of MDSCs to the primary cancer or the premetastatic niche. Tumor-derived CXCR2ligands (IL-8, CXCL1, CXCL2, and CXCL5) attract MDSCs to the tumor microenvironment [71-73] and inhibition of CXCR2 profoundly suppresses $\mathrm{Gr}^{-} \mathrm{1}^{+}$leukocyte migration into tumor [74]. CXCR2 is expressed on most of circulating G-MDSCs but not on M-MDSCs and is prerequisite for GMDSCs to be recruited to tumor microenvironment [12].

Tumor-derived inflammatory mediator $\mathrm{PGE}_{2}$ promotes CXCL12 production via EP2/4 receptor signaling and thus accumulates CXCR4-expressing MDSCs in human ovarian cancer [75]. On the other hand, CCR2 ${ }^{+}$M-MDSCs are recruited by tumor-derived CCL2 in mice and human [7678]. S100A8 and S100A9 not only activate MDSCs but also attract MDSCs by binding receptor for advanced glycation end products (RAGE) on MDSCs. Recruited MDSCs secrete S100A8/A9, resulting in further accumulation of MDSCs in human breast cancer [8].

\section{Other Functions of MDSCs in Cancer}

G-MDSCs promote tumor angiogenesis via secreting Bv8 which is regulated by STAT3 activation [79]. STAT3 activation also induces the secretion of VEGF and bFGF from MDSCs [80]. MDSCs also promote tumor-associated angiogenesis by secreting matrix metalloproteinase-9 (MMP-9) [54]. Accumulating evidences show that cancer cells disseminate at early phase of tumor progression. MDSCs facilitate cancer cell invasion and intravasation by secreting multiple proteolytic enzymes including MMPs which are necessary for extracellular matrix degradation and disruption of endothelial cadherins, adhesion proteins or basement membrane of vessels [81-83]. Epithelial-mesenchymal transition (EMT) is one of the steps for dissemination of cancer cells. When cancer cells undergo EMT, cancer cells lose epithelial markers and gain mesenchymal phenotypes. G-MDSCs induce EMT in cancer cells using TGF- $\beta$, epidermal growth factor (EGF), and hepatocyte growth factor (HGF) [73]. On the other hand, MDSCs also contribute to mesenchymal-epithelial transition (MET) of cancer cells by secreting versican [84]. This MDSC function supports cancer cells to colonize at metastatic niche.

MDSCs interact with cancer cells and induce microRNA101 (miR-101) expression. miR-101 subsequently decreases the corepressor gene C-terminal binding protein- 2 (CtBP2), which results in increased cancer cell stemness in ovarian cancer [85].
On the contrary to prometastatic functions of MDSCs, Gr- $1^{+}$myeloid cells generate a metastasis-resistant microenvironment in distant organs through the induction of thrombospondin-1 (Tsp-1) by tumor-derived prosaposin in mice bearing metastasis-incompetent tumors [86]. This may represent not only heterogeneity of MDSCs but also functional plasticity of MDSCs, and the activities of MDSCs might depend on a type of primary tumor. In addition,

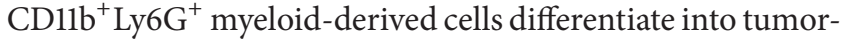
entrained neutrophils (TENs), which inhibit formation of premetastatic niche in the lungs [87]. It is unclear whether TENs represent differentiated stage of MDSCs or independently matured cells.

\section{Clinical Therapeutic Strategies Targeting MDSCs in Cancer}

Most of preclinical and clinical evidences indicate the association of MDSCs with poor prognostic outcome as well as immunosuppressive effect in tumor microenvironment both in primary and metastatic tumor regardless of the heterogeneity of MDSCs particularly in human cancer patients. The cancer-supportive activities provide a rationale for therapeutic approaches to target cancer-associated MDSCs. The strategies targeting MDSCs would be roughly divided into two approaches: (1) directly harnessing the mechanisms of MDSC expansion, recruitment, or immunosuppressive processes (Figure 2) to target the protumorigenic/prometastatic activities of MDSCs and (2) sensitizing other anticancer agents through suppressing MDSC accumulation.

Several potential strategies for targeting MDSCs can be proposed for each step of MDSC accumulation and the activities (Figure 2). First potential treatment strategy is inhibiting tumor-derived or MDSC-derived factors which expand and mobilize MDSCs from bone marrow or spleen. Several neutralizing antibodies or inhibitors against tumorderived factors or those receptors such as GM-CSF, GMCSF receptor (GM-CSFR) [64], M-CSF, M-CSF receptor (MCSFR) [88, 89], G-CSF [90], VEGF-A [91], or stem cell factor (SCF or KIT) [60] have been reported to inhibit MDSC expansion or mobilization. However, anti-VEGFA monoclonal antibody, bevacizumab, could not reduce the accumulation of MDSCs in human renal cell cancer [92]. Anti-IL-6 receptor monoclonal antibody neutralizes tumor-derived IL-6 and thus suppresses expansion of cancerassociated MDSCs [93]. Also, directly inhibiting MDSC proliferation from hematopoietic precursor cells in bone marrow or spleen would be an approach to suppress MDSC expansion as well as decreasing circulating MDSCs. Some chemotherapy drugs such as gemcitabine and 5-fluorouracil decrease circulating MDSCs [94, 95]. However, one study shows that combination of gemcitabine and capecitabine does not affect the levels of MDSCs in patients with advanced pancreatic cancer [96]. An aminobisphosphonate zoledronic acid (zoledronate) reduces mobilization of MDSCs through suppressing bone marrow progenitor-derived and tumorderived MMP-9 $[97,98]$ although one study reports that 


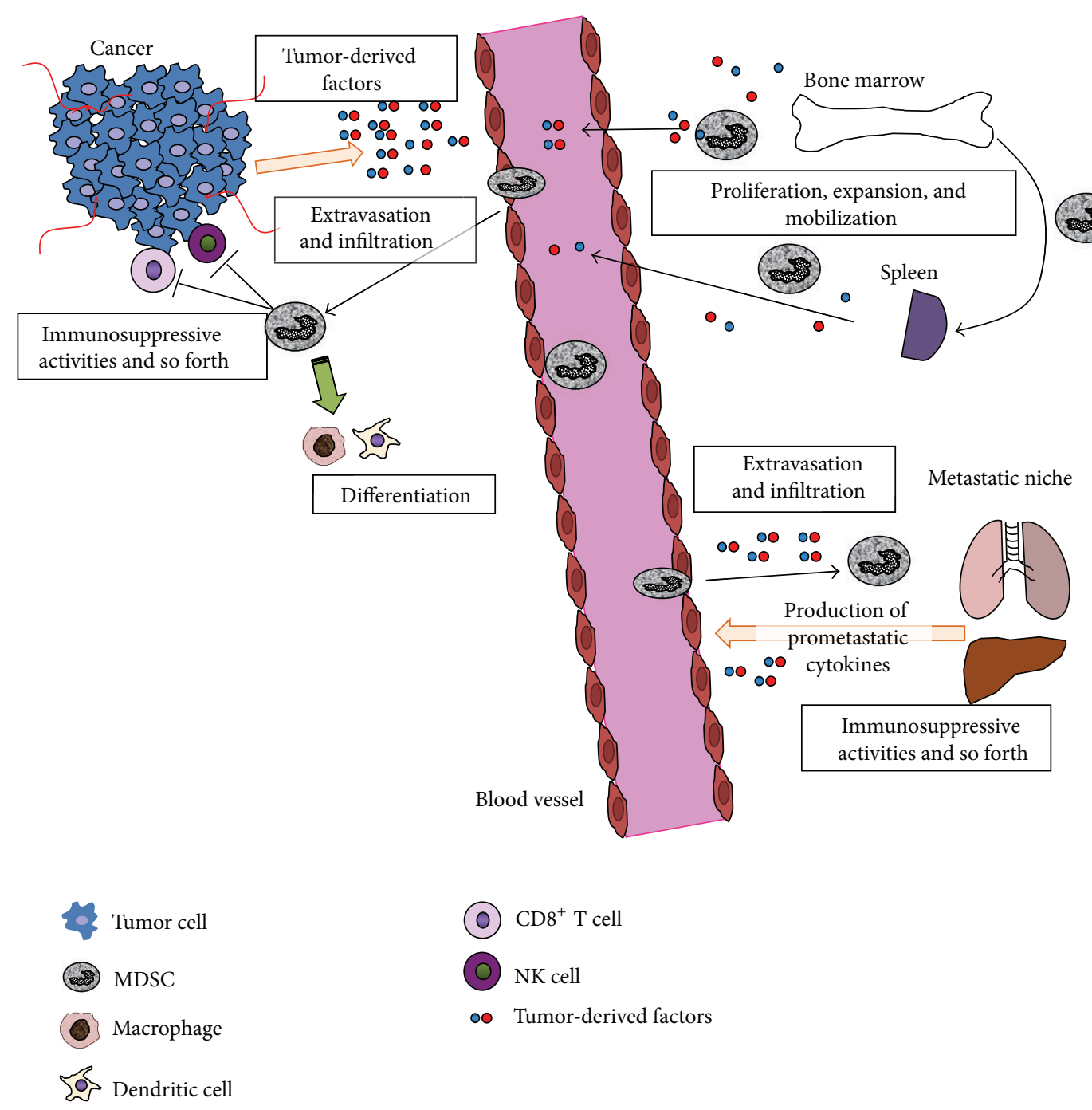

FIGURE 2: Schema of MDSC expansion and recruitment machinery. Tumor-derived factors (e.g., GM-CSF, IL-6, S100A8/A9, and PGE 2 ) promote proliferation, expansion, and mobilization of MDSCs from bone marrow hematopoietic progenitor cells, and tumor-derived chemokines (e.g., CXCL1/2 and CXCL12) recruit MDSCs to primary tumor and metastatic niche according to their chemokine gradients. Bone marrow-derived MDSC precursors are also arrested at marginal zone of spleen and migrate to the red pulp and proliferate. Recruited MDSCs support tumor progression by the immunosuppressive activities against cytotoxic $\mathrm{CD} 8^{+} \mathrm{T}$ cells and NK cells. M-MDSCs can differentiate to mature nonsuppressive dendritic cells or type 1 macrophages. MDSCs also facilitate tumor-associated angiogenesis and epithelial-mesenchymal transition of cancer cells, which results in invasion and extravasation. On the other hand, MDSCs can contribute to mesenchymal-epithelial transition at the metastatic niche.

zoledronic acid impairs tumor-associated macrophage proliferation but not MDSCs [99]. Sunitinib is a multikinase inhibitor which inhibits VEGFR1-3, platelet-derived growth factor receptor- (PDGFR-) $\alpha$ and $\beta$, stem cell factor receptor (c-Kit), FLT3, and RET [100]. Sunitinib also reduces MDSC proliferation [23, 101]. Vemurafenib is a highly specific inhibitor of mutant $\mathrm{B}-\mathrm{RAF}^{\mathrm{V} 600 \mathrm{E}}$ and suppresses the release of tumor-derived soluble factors involved in MDSC generation [102]. Peroxisome proliferator-activated receptor$\gamma(\operatorname{PPAR} \gamma)$ is an anti-inflammatory molecule expressed in myeloid-lineage. Dominant-negative PPAR $\gamma$ expression in myeloid cells reduces expansion of $\mathrm{CD}_{11 b^{+}} \mathrm{Ly}_{6 \mathrm{G}}{ }^{+}$population [103].
Of course, it is promising to inhibit accumulation of MDSCs by targeting aforementioned tumor-derived factors or tumor-related inflammatory mediators or by using chemotherapeutic agents or monoclonal antibodies which are thought to suppress expansion of MDSCs. However, some limitations should be considered particularly in clinical studies, that is, "cause or result" issue. The tumor-derived factors or inflammatory mediators can facilitate tumor progression by themselves. And the chemotherapeutic agents or monoclonal antibodies which are thought to inhibit MDSC accumulation also target cancer cells themselves, consequently leading to reduction of MDSCs. Accordingly, the attenuation of MDSC accumulation may, at least partly, 
reflect the reduction of the tumor burden caused by the therapeutic agents.

A second therapeutic strategy would be inhibiting MDSC recruitment from the circulation to the tumor microenvironment or to the peripheral lymphoid organs. Tumor-derived CXCR2-ligands, CXCL1, CXCL2, and CXCL5, have been known to promote recruitment of MDSCs to the site of tumor or to the premetastatic niche $[12,71-73,104]$. Since CXCR2 is mainly expressed on G-MDSCs, CXCR2 inhibition may impair the recruitment of G-MDSCs [12]. Accordingly, it is warranted to clarify the organ-specific preferences of MDSC types. Other antagonists or inhibitors for chemokine systems such as anti-CXCR4 antibody and CCL2 neutralizing antibody would have potential to inhibit MDSC accumulation $[4,75,105]$. CSF1R antagonist can suppress the infiltration of MDSCs and tumor-associated macrophages (TAMs) to the site of tumor $[88,89]$. Recently, one study suggested MDSC-specific peptides (H6 and G3) and generated peptideFc fusion proteins (peptibodies) which bind and affect both G-MDSCs and M-MDSCs [106]. These peptibodies specifically depleted MDSCs without affecting proinflammatory immune cell types such as mature dendritic cells. Since these peptibodies target only MDSCs, they have potential to solve aforementioned "cause or result" issue of MDSC-targeting therapies.

Thirdly, therapeutic strategy would involve directly blocking suppressive activities of MDSCs. Cyclooxygenase2 (COX-2) inhibitors suppress activation of MDSCs through CCL2, CXCL12, or $\mathrm{PGE}_{2}$ inhibition and increase cytotoxic T lymphocytes (CTLs) [11, 75, 107]. Phosphodiesterase-5 (PDE5) inhibitors (sildenafil, tadalafil, and vardenafil) are currently applied for clinical use in nonmalignant diseases (e.g., pulmonary hypertension). PDE-5 inhibitors increase infiltration of activated CTLs into tumor and tumor-induced T cell proliferation [108]. PDE-5 inhibitors restore $\zeta$-chain expression in TCR by decreasing MDSCs $[109,110]$. Importantly, PDE- 5 inhibitors downregulate expression of Argl, iNOS, and IL- $4 \alpha$ in MDSCs, which results in restoration of cytotoxic activities of T cells [108]. Synthetic triterpenoid C-28 methyl ester of 2-cyano-3,12-dioxooleana-1,9,-dien-28-oic acid (CDDO$\mathrm{Me}$, bardoxolone methyl) abrogates the immunosuppressive activities of MDSCs and restored immune responses in both preclinical murine model and patients with renal cell carcinoma [111].

A fourth strategy would be promoting the differentiation of MDSCs into mature, nonsuppressive cells. Alltrans retinoic acid (ATRA), a vitamin A derivative, induces MDSC differentiation into mature myeloid cells by upregulating glutathione synthase in MDSCs [112]. Removal of immature myeloid cells from DC fractions by ATRA restored the ability of DCs to stimulate antigen-specific $\mathrm{T}$ cell activity [113]. In patients with metastatic renal cell carcinoma, ATRA administration decreased circulating $\mathrm{CD}^{+} 3^{+} \mathrm{HLA}-\mathrm{DR}^{-} \mathrm{Lin}^{-/ \text {low }}$ MDSCs, which leads to improved myeloid/lymphoid DC ratio and antigen-specific $\mathrm{T}$ cell response [114]. Immune suppressive $\mathrm{CD} 34^{+}$progenitors (MDSCs) are increased in peripheral blood and tumors of patients with head and neck squamous cell cancer
(HNSCC). These CD34 ${ }^{+}$MDSCs isolated from peripheral blood of HNSCC patients can be differentiated into phenotypically and functionally DC-like cells in vitro, and 1,25dihydroxyvitamin D3 $\left(1,25(\mathrm{OH})_{2} \mathrm{D} 3\right)$ accelerates differentiation of MDSCs into the DC-like cells [115]. Indeed, 25hydroxyvitamin D3 reduced the circulating CD $34^{+}$MDSCs in HNSCC patients which resulted in increased levels of plasma IL-12 and IFN- $\gamma$ and T cell proliferation [116]. Although 25-hydroxyvitamin D3 alone failed to improve clinical outcome [116], it may have a potential to sensitize other chemotherapeutic agents by reducing MDSCs. One study shows that tumor necrosis factor- $\alpha$ (TNF- $\alpha$ ) blocks differentiation and augments suppressive activity of MDSCs in chronic inflammatory settings and that administration of a TNF- $\alpha$ antagonist, etanercept, reduces MDSCs' suppressive activity and promotes their maturation into dendritic cells and macrophages [117]. However, this study is based on chronic inflammation model and remains to be confirmed in tumor-bearing model as well.

Several preclinical studies have shown that MDSCs play a critical role in refractoriness against anticancer drugs such as bevacizumab, cyclophosphamide, anthracycline, and sunitinib $[6,8,9,118,119]$ (Table 1). Therefore, targeting MDSCs would lead to sensitizing these drugs. An anti-VEGF monoclonal antibody, bevacizumab, and a multikinase inhibitor, sunitinib, upregulate Bv8 production from MDSCs, unexpectedly leading to tumor-associated angiogenesis. Indeed, anti-Bv8 antibody treatment restores antiangiogenic effects and shows additive cytotoxic effect on those of anti-VEGF antibody therapy [118]. Anthracycline and cyclophosphamide (AC) regimen enhances production of tumor necrosis factor$\alpha$ (TNF- $\alpha$ ) from tumor stromal cells and endothelial cells. Consequently, TNF- $\alpha$ boosts CXCL1/2 production by cancer cells through NF- $\kappa \mathrm{B}$ signaling. CXCL1/2 promote recruitment of G-MDSCs which secrete S100A8/9, which results in amplifying the CXCL1/2-S100A8/9 loop and causing increased cancer cell survival, metastasis, and chemoresistance [8]. Accordingly, CXCR2 blockade may impair this vicious cycle. Interestingly, tumor-derived G-CSF induced MDSCs may contribute to radioresistant feature in uterine cervical cancer [120]. Anti-Gr-1 neutralizing antibody or MDSC depletion by splenectomy restored radiosensitivity in cervical cancer xenografts. Collectively, several chemotherapeutic agents or radiotherapy unexpectedly stimulates secretion of tumor-derived factor, which leads to expansion of MDSCs critically causing refractoriness against the treatments. To break this vicious cycle by inhibiting recruitment of MDSCs may sensitize these chemotherapeutic agents or radiotherapy and prevent the refractoriness against the anticancer therapies.

A variety of promising combination therapies targeting MDSCs have been proposed. Combination of antigenspecific peptide and ATRA significantly increases and prolongs antigen-specific $\mathrm{T}$ cell response [121]. In patients with extensive stage small cell lung cancer, ATRA improved the immune response to vaccination by significant reduction of CD33+HLA-DR ${ }^{-} \mathrm{Lin}^{-/ \text {low }}$ MDSCs and consequent restored antigen-specific $\mathrm{T}$ cell response [122]. Of note, 
TABLE 1: MDSCs-mediated refractoriness to chemotherapy or radiotherapy.

\begin{tabular}{lll}
\hline Treatment & Mechanisms & References \\
\hline Anti-VEGF antibody (bevacizumab) & Bv8 production in MDSCs & [118] \\
\hline Anthracycline/cyclophosphamide & $\begin{array}{l}\text { S100A8/9 production in accumulated MDSCs via secretion of } \\
\text { CXCL1/2 by cancer cells }\end{array}$ \\
\hline Tyrosine kinase inhibitor (sunitinib) & $\begin{array}{l}\text { Bv8 production in MDSCs } \\
\text { pSTAT5-dependent pathway via GM-CSF production }\end{array}$ \\
\hline Radiotherapy & G-CSF-mediated MDSC accumulation & {$[118,119]$} \\
\hline
\end{tabular}

ATRA administration does not cause significant toxicity [114]. HER2/neu is a self-antigen with poor immunogenicity which is overexpressed in human cancer cells such as breast cancer. Gemcitabine treatment with HER2/neu vaccine and antiglucocorticoid-induced tumor necrosis factor receptor (TNFR) family-related receptor (GITR) antibody is effective in HER2/neu-positive tumor [123], in which gemcitabine attenuates the tumor immune suppression through dramatic reduction of MDSCs. Accordingly, combination therapy of immunotherapies and gemcitabine would be a promising treatment option. Sunitinib, a small molecule inhibitor of multiple receptor tyrosine kinases, reduces MDSCs in peripheral blood of patients with renal cell carcinoma [101]. The addition of sunitinib to low-dose radiation additionally suppressed tumor growth in glioblastoma [124]; however, the mechanisms of the tumor suppressive effect in this combination therapy are still unclear. The programmed death 1 (PD1) receptor is an important immune checkpoint which is expressed on T cells, and PD1 signaling inhibits $\mathrm{T}$ cell receptor-mediated activation [125]. Recently, clinical evidences have shown limited efficacy of anti-PD1 monoclonal antibody in a minority of cancer patients. Rhabdomyosarcoma attenuates the efficacy of anti-PD1 therapy by inducing expansion of CXCR2 ${ }^{+} \mathrm{CD}_{11 b^{+}} \mathrm{Ly}_{6} \mathrm{G}^{\text {high }}$ G-MDSCs in preclinical model [126]. Anti-CXCR2 monoclonal antibody therapy improved significant antitumor effects of anti-PD1 treatment. These findings suggest that inhibition of CXCR2 ${ }^{+} \mathrm{G}-$ MDSC tumor trafficking may sensitize and enhance anti-PD1 monoclonal antibody therapy in other cancers. Collectively, targeting MDSCs is a promising strategy to improve or increase immunotherapies against cancers.

One interesting preclinical study indicates the application of MDSCs as a vehicle to deliver radioisotope-coupled attenuated variant of Listeria monocytogenes to tumor sites [127]. This may be applicable to other anticancer agents.

On the other hand, as various studies show that circulating MDSC levels are correlated with tumor stages [21, 128], MDSCs would be a good marker for a potential relapse of tumor or a surrogate marker which represents treatment efficacy. For instance, an elevated activity of circulating MDSCs indicated by increased NO production is suggested to be an early marker of incomplete treatment and a potential relapse of cancer in non-small cell lung cancer [129]. Also, MDSC levels in peripheral blood may predict chemotherapy failure in patients with pancreatic adenocarcinoma [27]. The sensitivity and specificity circulating MDSC levels or the activation markers are still elusive.

\section{Summary}

Immune evasion is a hallmark of cancer, and cancerinduced MDSCs play an essential role in tumor progression through tumor-associated immunosuppression. Therefore, it is a promising approach to break the vicious cycle in which MDSCs are expanded and recruited to support tumor progression. Several approaches have been sought, for example, inhibition of tumor-derived factors, suppression of generation and expansion of MDSCs from hematopoietic progenitors, blockade of MDSC trafficking and infiltration, harnessing immune suppressive activities of MDSCs, or facilitating differentiation of MDSCs into mature nonsuppressive cells. Furthermore, targeting MDSCs may enhance and sensitize the effects of chemotherapies, vaccine therapies, or radiotherapies. However, MDSCs are composed of heterogenous populations which are probably in different stages of differentiation and may have different activity in individuals with cancer. Importantly, markers of MDSCs in human are much more complicated than in mice, leading to further heterogeneity and difficulty. MDSC biology including these limitations remains to be elucidated for development of MDSC-targeting therapy, patient selection, and decision of treatment strategy.

\section{Conflict of Interests}

The authors declare no conflict of interests.

\section{Acknowledgment}

This work was supported by the Uehara Memorial Foundation Research Fellowship (to Hiroshi Katoh).

\section{References}

[1] L. M. Coussens and Z. Werb, "Inflammation and cancer," Nature, vol. 420, no. 6917, pp. 860-867, 2002.

[2] A. Orimo, P. B. Gupta, D. C. Sgroi et al., "Stromal fibroblasts present in invasive human breast carcinomas promote tumor growth and angiogenesis through elevated SDF-1/CXCL12 secretion," Cell, vol. 121, no. 3, pp. 335-348, 2005.

[3] H. Katoh, K. Hosono, Y. Ito et al., "COX-2 and prostaglandin $\mathrm{EP} 3 / \mathrm{EP} 4$ signaling regulate the tumor stromal proangiogenic microenvironment via CXCL12-CXCR4 chemokine systems," The American Journal of Pathology, vol.176, no. 3, pp. 1469-1483, 2010. 
[4] D. I. Gabrilovich and S. Nagaraj, "Myeloid-derived suppressor cells as regulators of the immune system," Nature Reviews Immunology, vol. 9, no. 3, pp. 162-174, 2009.

[5] S. Ostrand-Rosenberg and P. Sinha, "Myeloid-derived suppressor cells: linking inflammation and cancer," The Journal of Immunology, vol. 182, no. 8, pp. 4499-4506, 2009.

[6] C. M. Diaz-Montero, M. L. Salem, M. I. Nishimura, E. GarrettMayer, D. J. Cole, and A. J. Montero, "Increased circulating myeloid-derived suppressor cells correlate with clinical cancer stage, metastatic tumor burden, and doxorubicin-cyclophosphamide chemotherapy," Cancer Immunology, Immunotherapy, vol. 58, no. 1, pp. 49-59, 2009.

[7] S. Mandruzzato, S. Solito, E. Falisi et al., "IL4R $\alpha^{+}$myeloidderived suppressor cell expansion in cancer patients," Journal of Immunology, vol. 182, no. 10, pp. 6562-6568, 2009.

[8] S. Acharyya, T. Oskarsson, S. Vanharanta et al., "A CXCL1 paracrine network links cancer chemoresistance and metastasis," Cell, vol. 150, no. 1, pp. 165-178, 2012.

[9] F. Shojaei, X. Wu, A. K. Malik et al., "Tumor refractoriness to

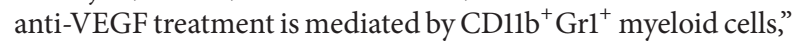
Nature Biotechnology, vol. 25, no. 8, pp. 911-920, 2007.

[10] A. S. Pak, M. A. Wright, J. P. Matthews, S. L. Collins, G. J. Petruzzelli, and M. R. I. Young, "Mechanisms of immune suppression in patients with head and neck cancer: presence of $\mathrm{CD} 34^{+}$cells which suppress immune functions within cancers that secrete granulocyte-macrophage colony-stimulating factor," Clinical Cancer Research, vol. 1, no. 1, pp. 95-103, 1995.

[11] J. E. Talmadge and D. I. Gabrilovich, "History of myeloidderived suppressor cells," Nature Reviews Cancer, vol. 13, no. 10, pp. 739-752, 2013.

[12] H. Katoh, D. Wang, T. Daikoku, H. Sun, S. K. Dey, and R. N. DuBois, "CXCR2-expressing myeloid-derived suppressor cells are essential to promote colitis-associated tumorigenesis," Cancer Cell, vol. 24, no. 5, pp. 631-644, 2013.

[13] J.-I. Youn, S. Nagaraj, M. Collazo, and D. I. Gabrilovich, "Subsets of myeloid-derived suppressor cells in tumor-bearing mice," The Journal of Immunology, vol. 181, no. 8, pp. 5791-5802, 2008.

[14] I. Younos, M. Donkor, T. Hoke et al., "Tumor- and organdependent infiltration by myeloid-derived suppressor cells," International Immunopharmacology, vol. 11, no. 7, pp. 816-826, 2011.

[15] J.-I. Youn, M. Collazo, I. N. Shalova, S. K. Biswas, and D. I. Gabrilovich, "Characterization of the nature of granulocytic myeloid-derived suppressor cells in tumor-bearing mice," Journal of Leukocyte Biology, vol. 91, no. 1, pp. 167-181, 2012.

[16] S. Kusmartsev, Z. Su, A. Heiser et al., "Reversal of myeloid cellmediated immunosuppression in patients with metastatic renal cell carcinoma," Clinical Cancer Research, vol. 14, no. 24, pp. 8270-8278, 2008.

[17] H.-L. Sun, X. Zhou, Y.-F. Xue et al., "Increased frequency and clinical significance of myeloidderived suppressor cells in human colorectal carcinoma," World Journal of Gastroenterology, vol. 18, no. 25, pp. 3303-3309, 2012.

[18] P. Shen, A. Wang, M. He, Q. Wang, and S. Zheng, "Increased circulating Lin," Hepatology Research, vol. 44, no. 6, pp. 639650, 2014.

[19] M. K. Srivastava, J. J. Bosch, J. A. Thompson, B. R. Ksander, M. J. Edelman, and S. Ostrand-Rosenberg, "Lung cancer patients' $\mathrm{CD}^{+}{ }^{+} \mathrm{T}$ cells are activated in vitro by MHC II cell-based vaccines despite the presence of myeloid-derived suppressor cells," Cancer Immunology, Immunotherapy, vol. 57, no. 10, pp. 1493-1504, 2008.
[20] J. Yu, W. Du, F. Yan et al., "Myeloid-derived suppressor cells suppress antitumor immune responses through IDO expression and correlate with lymph node metastasis in patients with breast cancer," The Journal of Immunology, vol. 190, no. 7, pp. 37833797, 2013.

[21] B. Zhang, Z. Wang, L. Wu et al., "Circulating and tumorinfiltrating myeloid-derived suppressor cells in patients with colorectal carcinoma," PLoS ONE, vol. 8, no. 2, Article ID e57114, 2013.

[22] S. Brandau, S. Trellakis, K. Bruderek et al., "Myeloid-derived suppressor cells in the peripheral blood of cancer patients contain a subset of immature neutrophils with impaired migratory properties," Journal of Leukocyte Biology, vol. 89, no. 2, pp. 311317, 2011.

[23] J. S. Ko, P. Rayman, J. Ireland et al., "Direct and differential suppression of myeloid-derived suppressor cell subsets by sunitinib is compartmentally constrained," Cancer Research, vol. 70, pp. 3526-3536, 2010.

[24] C. Y. Liu, Y. M. Wang, C. L. Wang et al., "Population alterations of 1 -arginase- and inducible nitric oxide synthase-

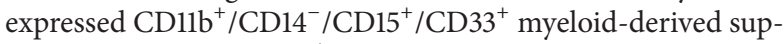
pressor cells and $\mathrm{CD}^{+} \mathrm{T}$ lymphocytes in patients with advanced-stage non-small cell lung cancer," Journal of Cancer Research and Clinical Oncology, vol. 136, no. 1, pp. 35-45, 2010.

[25] B. L. Mundy-Bosse, L. M. Thornton, H.-C. Yang, B. L. Andersen, and W. E. Carson, "Psychological stress is associated with altered levels of myeloid-derived suppressor cells in breast cancer patients," Cellular Immunology, vol. 270, no. 1, pp. 80-87, 2011.

[26] Y. S. Khaled, B. J. Ammori, and E. Elkord, "Increased levels of granulocytic myeloid-derived suppressor cells in peripheral blood and tumour tissue of pancreatic cancer patients," Journal of Immunology Research, vol. 2014, Article ID 879897, 9 pages, 2014.

[27] J. Markowitz, T. R. Brooks, M. C. Duggan et al., "Patients with pancreatic adenocarcinoma exhibit elevated levels of myeloidderived suppressor cells upon progression of disease," Cancer Immunology, Immunotherapy, vol. 64, no. 2, pp. 149-159, 2015.

[28] M. Idorn, T. Køllgaard, P. Kongsted, L. Sengeløv, and P. thor Straten, "Correlation between frequencies of blood monocytic myeloid-derived suppressor cells, regulatory $\mathrm{T}$ cells and negative prognostic markers in patients with castration-resistant metastatic prostate cancer," Cancer Immunology, Immunotherapy, vol. 63, no. 11, pp. 1177-1187, 2014.

[29] G. Wald, K. T. Barnes, M. T. Bing et al., "Minimal changes in the systemic immune response after nephrectomy of localized renal masses," Urologic Oncology, vol. 32, pp. 589-600, 2014.

[30] Y. Mao, I. Poschke, E. Wennerberg et al., "Melanomaeducated $\mathrm{CD} 14^{+}$cells acquire a myeloid-derived suppressor cell phenotype through COX-2-dependent mechanisms," Cancer Research, vol. 73, no. 13, pp. 3877-3887, 2013.

[31] B. Hoechst, L. A. Ormandy, M. Ballmaier et al., "A new population of myeloid-derived suppressor cells in hepatocellular carcinoma patients induces CD $4^{+} \mathrm{CD} 25^{+}$Foxp $3^{+} \mathrm{T}$ cells," Gastroenterology, vol. 135, no. 1, pp. 234-243, 2008.

[32] D. Vasquez-Dunddel, F. Pan, Q. Zeng et al., "STAT3 regulates arginase-i in myeloid-derived suppressor cells from cancer patients," The Journal of Clinical Investigation, vol. 123, no. 4, pp. 1580-1589, 2013.

[33] J. Jiang, W. Guo, and X. Liang, "Phenotypes, accumulation, and functions of myeloid-derived suppressor cells and associated 
treatment strategies in cancer patients," Human Immunology, vol. 75, no. 11, pp. 1128-1137, 2014.

[34] A. C. Ochoa, A. H. Zea, C. Hernandez, and P. C. Rodriguez, "Arginase, prostaglandins, and myeloid-derived suppressor cells in renal cell carcinoma," Clinical Cancer Research, vol. 13, no. 2, pp. 721s-726s, 2007.

[35] P. C. Rodriguez, C. P. Hernandez, D. Quiceno et al., "Arginase I in myeloid suppressor cells is induced by COX-2 in lung carcinoma," The Journal of Experimental Medicine, vol. 202, no. 7, pp. 931-939, 2005.

[36] S. Ostrand-Rosenberg, "Myeloid-derived suppressor cells: more mechanisms for inhibiting antitumor immunity," Cancer Immunology, Immunotherapy, vol. 59, no. 10, pp. 1593-1600, 2010.

[37] S. Solito, E. Falisi, C. M. Diaz-Montero et al., "A human promyelocytic-like population is responsible for the immune suppression mediated by myeloid-derived suppressor cells," Blood, vol. 118, no. 8, pp. 2254-2265, 2011.

[38] K. Movahedi, M. Guilliams, J. van den Bossche et al., "Identification of discrete tumor-induced myeloid-derived suppressor cell subpopulations with distinct T cell suppressive activity," Blood, vol. 111, no. 8, pp. 4233-4244, 2008.

[39] V. Bronte, P. Serafini, C. de Santo et al., "IL-4-induced arginase 1 suppresses alloreactive $\mathrm{T}$ cells in tumor-bearing mice," The Journal of Immunology, vol. 170, no. 1, pp. 270-278, 2003.

[40] S. Grivennikov, E. Karin, J. Terzic et al., "IL-6 and Stat3 are required for survival of intestinal epithelial cells and development of colitis-associated cancer," Cancer Cell, vol. 15, no. 2, pp. 103-113, 2009.

[41] Z.-J. Jiao, J.-J. Gao, S.-H. Hua et al., "Correlation between circulating myeloid-derived suppressor cells and Th17 cells in esophageal cancer," World Journal of Gastroenterology, vol. 18, no. 38, pp. 5454-5461, 2012.

[42] M. G. Lechner, C. Megiel, S. M. Russell et al., "Functional characterization of human $\mathrm{Cd}_{3} 3^{+}$And $\mathrm{Cd}_{11 b^{+}}$myeloid-derived suppressor cell subsets induced from peripheral blood mononuclear cells co-cultured with a diverse set of human tumor cell lines," Journal of Translational Medicine, vol. 9, article 90, 2011.

[43] A. Huang, B. Zhang, B. Wang, F. Zhang, K. Fan, and Y. Guo, "Increased $\mathrm{CD} 14^{+} \mathrm{HLA}-\mathrm{DR}^{-/ \text {low }}$ myeloid-derived suppressor cells correlate with extrathoracic metastasis and poor response to chemotherapy in non-small cell lung cancer patients," Cancer Immunology, Immunotherapy, vol. 62, no. 9, pp. 1439-1451, 2013.

[44] G. Angelini, S. Gardella, M. Ardy et al., "Antigen-presenting dendritic cells provide the reducing extracellular microenvironment required for T lymphocyte activation," Proceedings of the National Academy of Sciences of the United States of America, vol. 99, no. 3, pp. 1491-1496, 2002.

[45] M. K. Srivastava, P. Sinha, V. K. Clements, P. Rodriguez, and S. Ostrand-Rosenberg, "Myeloid-derived suppressor cells inhibit T-cell activation by depleting cystine and cysteine," Cancer Research, vol. 70, no. 1, pp. 68-77, 2010.

[46] H. Zhang, I. Maric, M. J. DiPrima et al., "Fibrocytes represent a novel MDSC subset circulating in patients with metastatic cancer," Blood, vol. 122, no. 7, pp. 1105-1113, 2013.

[47] C. Liu, S. Yu, J. Kappes et al., "Expansion of spleen myeloid suppressor cells represses NK cell cytotoxicity in tumor-bearing host," Blood, vol. 109, no. 10, pp. 4336-4342, 2007.

[48] B. Hoechst, T. Voigtlaender, L. Ormandy et al., "Myeloid derived suppressor cells inhibit natural killer cells in patients with hepatocellular carcinoma via the NKp30 receptor," Hepatology, vol. 50, no. 3, pp. 799-807, 2009.
[49] S. K. Bunt, V. K. Clements, E. M. Hanson, P. Sinha, and S. Ostrand-Rosenberg, "Inflammation enhances myeloid-derived suppressor cell cross-talk by signaling through Toll-like receptor 4," Journal of Leukocyte Biology, vol. 85, no. 6, pp. 996-1004, 2009.

[50] J. Gao, Y. Wu, Z. Su et al., "Infiltration of alternatively activated macrophages in cancer tissue is associated with MDSC and Th2 polarization in patients with esophageal cancer," PLOS ONE, vol. 9, no. 8, Article ID e104453, 2014.

[51] P. Serafini, R. Carbley, K. A. Noonan, G. Tan, V. Bronte, and I. Borrello, "High-dose granulocyte-macrophage colonystimulating factor-producing vaccines impair the immune response through the recruitment of myeloid suppressor cells," Cancer Research, vol. 64, no. 17, pp. 6337-6343, 2004.

[52] S. K. Bunt, L. Yang, P. Sinha, V. K. Clements, J. Leips, and S. Ostrand-Rosenberg, "Reduced inflammation in the tumor microenvironment delays the accumulation of myeloid-derived suppressor cells and limits tumor progression," Cancer Research, vol. 67, no. 20, pp. 10019-10026, 2007.

[53] D. Gabrilovich, T. Ishida, T. Oyama et al., "Vascular endothelial growth factor inhibits the development of dendritic cells and dramatically affects the differentiation of multiple hematopoietic lineages in vivo," Blood, vol. 92, no. 11, pp. 4150-4166, 1998.

[54] T. Condamine, I. Ramachandran, J. I. Youn, and D. I. Gabrilovich, "Regulation of tumor metastasis by myeloidderived suppressor cells," Annual Review of Medicine, vol. 66, no. 1, pp. 97-110, 2015.

[55] J. D. Waight, C. Netherby, M. L. Hensen et al., "Myeloid-derived suppressor cell development is regulated by a STAT/IRF-8 axis," Journal of Clinical Investigation, vol. 123, no. 10, pp. 4464-4478, 2013.

[56] X. Zhao, L. Rong, X. Li et al., “TNF signaling drives myeloidderived suppressor cell accumulation," Journal of Clinical Investigation, vol. 122, no. 11, pp. 4094-4104, 2012.

[57] N. Obermajer, R. Muthuswamy, J. Lesnock, R. P. Edwards, and P. Kalinski, "Positive feedback between PGE2 and COX2 redirects the differentiation of human dendritic cells toward stable myeloid-derived suppressor cells," Blood, vol. 118, no. 20, pp. 5498-5505, 2011.

[58] N. Obermajer, J. L. Wong, R. P. Edwards, K. Odunsi, K. Moysich, and P. Kalinski, " $\mathrm{PGE}_{2}$-driven induction and maintenance of cancer-associated myeloid-derived suppressor cells," Immunological Investigations, vol. 41, no. 6-7, pp. 635-657, 2012.

[59] P. Sinha, V. K. Clements, A. M. Fulton, and S. OstrandRosenberg, "Prostaglandin E2 promotes tumor progression by inducing myeloid-derived suppressor cells," Cancer Research, vol. 67, no. 9, pp. 4507-4513, 2007.

[60] P.-Y. Pan, G. X. Wang, B. Yin et al., "Reversion of immune tolerance in advanced malignancy: modulation of myeloidderived suppressor cell development by blockade of stem-cell factor function," Blood, vol. 111, no. 1, pp. 219-228, 2008.

[61] J. LeCouter, C. Zlot, M. Tejada, F. Peale, and N. Ferrara, "Bv8 and endocrine gland-derived vascular endothelial growth factor stimulate hematopoiesis and hematopoietic cell mobilization," Proceedings of the National Academy of Sciences of the United States of America, vol. 101, no. 48, pp. 16813-16818, 2004.

[62] Y. Nefedova, M. Huang, S. Kusmartsev et al., "Hyperactivation of STAT3 is involved in abnormal differentiation of dendritic cells in cancer," Journal of Immunology, vol. 172, no. 1, pp. 464474, 2004.

[63] C. M. Diaz-Montero, J. Finke, and A. J. Montero, "Myeloidderived suppressor cells in cancer: therapeutic, predictive, and 
prognostic implications," Seminars in Oncology, vol. 41, no. 2, pp. 174-184, 2014.

[64] L. J. Bayne, G. L. Beatty, N. Jhala et al., "Tumor-derived granulocyte-macrophage colony-stimulating factor regulates myeloid inflammation and $\mathrm{T}$ cell immunity in pancreatic cancer," Cancer Cell, vol. 21, no. 6, pp. 822-835, 2012.

[65] Y. Pylayeva-Gupta, K. E. Lee, C. H. Hajdu, G. Miller, and D. BarSagi, "Oncogenic Kras-induced GM-CSF production promotes the development of pancreatic neoplasia," Cancer Cell, vol. 21, no. 6, pp. 836-847, 2012.

[66] P. Cheng, C. A. Corzo, N. Luetteke et al., "Inhibition of dendritic cell differentiation and accumulation of myeloid-derived suppressor cells in cancer is regulated by S100A9 protein," The Journal of Experimental Medicine, vol. 205, no. 10, pp. 22352249, 2008.

[67] P. Sinha, C. Okoro, D. Foell, H. H. Freeze, S. OstrandRosenberg, and G. Srikrishna, "Proinflammatory S100 proteins regulate the accumulation of myeloid-derived suppressor cells," Journal of Immunology, vol. 181, no. 7, pp. 4666-4675, 2008.

[68] J. E. Talmadge, K. C. Hood, L. C. Zobel, L. R. Shafer, M. Coles, and B. Toth, "Chemoprevention by cyclooxygenase- 2 inhibition reduces immature myeloid suppressor cell expansion," International Immunopharmacology, vol. 7, no. 2, pp. 140-151, 2007.

[69] I. Marigo, E. Bosio, S. Solito et al., "Tumor-induced tolerance and immune suppression depend on the $\mathrm{C} / \mathrm{EBP} \beta$ transcription factor," Immunity, vol. 32, no. 6, pp. 790-802, 2010.

[70] B. Höchst, F. A. Schildberg, P. Sauerborn et al., "Activated human hepatic stellate cells induce myeloid derived suppressor cells from peripheral blood monocytes in a CD44-dependent fashion," Journal of Hepatology, vol. 59, no. 3, pp. 528-535, 2013.

[71] S. Asfaha, A. N. Dubeykovskiy, H. Tomita et al., "Mice that express human interleukin-8 have increased mobilization of immature myeloid cells, which exacerbates inflammation and accelerates colon carcinogenesis," Gastroenterology, vol. 144, no. 1, pp. 155-166, 2013.

[72] M. K. Connolly, J. M.-S. Clair, A. S. Bedrosian et al., "Distinct populations of metastases-enabling myeloid cells expand in the liver of mice harboring invasive and preinvasive intraabdominal tumor," Journal of Leukocyte Biology, vol. 87, no. 4, pp. 713-725, 2010.

[73] B. Toh, X. Wang, J. Keeble et al., "Mesenchymal transition and dissemination of cancer cells is driven by myeloid-derived suppressor cells infiltrating the primary tumor," PLoS Biology, vol. 9, no. 9, Article ID e1001162, 2011.

[74] T. Jamieson, M. Clarke, C. W. Steele et al., "Inhibition of CXCR2 profoundly suppresses inflammation-driven and spontaneous tumorigenesis," The Journal of Clinical Investigation, vol. 122, no. 9, pp. 3127-3144, 2012.

[75] N. Obermajer, R. Muthuswamy, K. Odunsi, R. P. Edwards, and P. Kalinski, "PGE 2-induced CXCL 12 production and CXCR4 expression controls the accumulation of human MDSCs in ovarian cancer environment," Cancer Research, vol. 71, no. 24, pp. 7463-7470, 2011.

[76] B. Huang, Z. Lei, J. Zhao et al., "CCL2/CCR2 pathway mediates recruitment of myeloid suppressor cells to cancers," Cancer Letters, vol. 252, no. 1, pp. 86-92, 2007.

[77] A. M. Lesokhin, T. M. Hohl, S. Kitano et al., "Monocytic $\mathrm{CCR}^{+}$myeloid-derived suppressor cells promote immune escape by limiting activated CD8 T-cell infiltration into the tumor microenvironment," Cancer Research, vol. 72, no. 4, pp. 876-886, 2012.
[78] Y. Sawanobori, S. Ueha, M. Kurachi et al., "Chemokinemediated rapid turnover of myeloid-derived suppressor cells in tumor-bearing mice," Blood, vol. 111, no. 12, pp. 5457-5466, 2008.

[79] X. Qu, G. Zhuang, L. Yu, G. Meng, and N. Ferrara, "Induction of Bv8 Expression by granulocyte colony-stimulating factor in

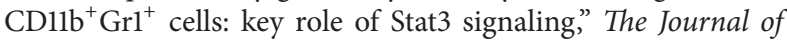
Biological Chemistry, vol. 287, no. 23, pp. 19574-19584, 2012.

[80] M. Kujawski, M. Kortylewski, H. Lee, A. Herrmann, H. Kay, and $\mathrm{H}$. Yu, "Stat3 mediates myeloid cell-dependent tumor angiogenesis in mice," The Journal of Clinical Investigation, vol. 118, no. 10, pp. 3367-3377, 2008.

[81] Y. Liu, L. Lai, Q. Chen et al., "MicroRNA-494 is required for the accumulation and functions of tumor-expanded myeloidderived suppressor cells via targeting of PTEN," The Journal of Immunology, vol. 188, no. 11, pp. 5500-5510, 2012.

[82] L. Yang, L. M. DeBusk, K. Fukuda et al., "Expansion of myeloid immune suppressor Gr+CD11b+ cells in tumor-bearing host directly promotes tumor angiogenesis," Cancer Cell, vol. 6, no. 4, pp. 409-421, 2004.

[83] L. Yang, J. Huang, X. Ren et al., "Abrogation of TGF beta signaling in mammary carcinomas recruits Gr-1+CD11b+ myeloid cells that promote metastasis," Cancer Cell, vol. 13, no. 1, pp. 2335, 2008.

[84] D. Gao, N. Joshi, H. Choi et al., "Myeloid progenitor cells in the premetastatic lung promote metastases by inducing mesenchymal to epithelial transition," Cancer Research, vol. 72, no. 6, pp. 1384-1394, 2012.

[85] T. X. Cui, I. Kryczek, L. Zhao et al., "Myeloid-derived suppressor cells enhance stemness of cancer cells by inducing microRNA101 and suppressing the corepressor CTBP2," Immunity, vol. 39, no. 3, pp. 611-621, 2013.

[86] R. Catena, N. Bhattacharya, T. El Rayes et al., "Bone marrowderived $\mathrm{Grl}^{+}$cells can generate a metastasis-resistant microenvironment via induced secretion of thrombospondin-1," Cancer Discovery, vol. 3, no. 5, pp. 578-589, 2013.

[87] Z. Granot, E. Henke, E. A. Comen, T. A. King, L. Norton, and R. Benezra, "Tumor entrained neutrophils inhibit seeding in the premetastatic lung," Cancer Cell, vol. 20, no. 3, pp. 300-314, 2011.

[88] D. G. DeNardo, D. J. Brennan, E. Rexhepaj et al., "Leukocyte complexity predicts breast cancer survival and functionally regulates response to chemotherapy," Cancer Discovery, vol. 1, no. 1, pp. 54-67, 2011.

[89] S. J. Priceman, J. L. Sung, Z. Shaposhnik et al., "Targeting distinct tumor-infiltrating myeloid cells by inhibiting CSF-1 receptor: combating tumor evasion of antiangiogenic therapy," Blood, vol. 115, no. 7, pp. 1461-1471, 2010.

[90] F. Shojaei, X. Wu, X. Qu et al., "G-CSF-initiated myeloid cell mobilization and angiogenesis mediate tumor refractoriness to anti-VEGF therapy in mouse models," Proceedings of the National Academy of Sciences of the United States of America, vol. 106, no. 16, pp. 6742-6747, 2009.

[91] B. Almand, J. R. Resser, B. Lindman et al., "Clinical significance of defective dendritic cell differentiation in cancer," Clinical Cancer Research, vol. 6, no. 5, pp. 1755-1766, 2000.

[92] P. C. Rodriguez, M. S. Ernstoff, C. Hernandez et al., "Arginase I-producing myeloid-derived suppressor cells in renal cell carcinoma are a subpopulation of activated granulocytes," Cancer Research, vol. 69, no. 4, pp. 1553-1560, 2009.

[93] K. Sumida, D. Wakita, Y. Narita et al., "Anti-IL-6 receptor mAb eliminates myeloid-derived suppressor cells and inhibits tumor 
growth by enhancing T-cell responses," European Journal of Immunology, vol. 42, no. 8, pp. 2060-2072, 2012.

[94] E. Suzuki, V. Kapoor, A. S. Jassar, L. R. Kaiser, and S. M. Albelda, "Gemcitabine selectively eliminates splenic $\mathrm{Gr}-\mathrm{1}^{+}$/ $\mathrm{CD} 1 \mathrm{~b}^{+}$myeloid suppressor cells in tumor-bearing animals and enhances antitumor immune activity," Clinical Cancer Research, vol. 11, no. 18, pp. 6713-6721, 2005.

[95] J. Vincent, G. Mignot, F. Chalmin et al., "5-Fluorouracil selectively kills tumor-associated myeloid-derived suppressor cells resulting in enhanced T cell-dependent antitumor immunity," Cancer Research, vol. 70, pp. 3052-3061, 2010.

[96] N. E. Annels, V. E. Shaw, R. F. Gabitass et al., "The effects of gemcitabine and capecitabine combination chemotherapy and of low-dose adjuvant GM-CSF on the levels of myeloid-derived suppressor cells in patients with advanced pancreatic cancer," Cancer Immunology, Immunotherapy, vol. 63, no. 2, pp. 175-183, 2014.

[97] C. Melani, S. Sangaletti, F. M. Barazzetta, Z. Werb, and M. P. Colombo, "Amino-biphosphonate-mediated MMP-9 inhibition breaks the tumor-bone marrow axis responsible for myeloidderived suppressor cell expansion and macrophage infiltration in tumor stroma," Cancer Research, vol. 67, no. 23, pp. 1143811446, 2007.

[98] M. R. Porembka, J. B. Mitchem, B. A. Belt et al., "Pancreatic adenocarcinoma induces bone marrow mobilization of myeloid-derived suppressor cells which promote primary tumor growth," Cancer Immunology, Immunotherapy, vol. 61, no. 9, pp. 1373-1385, 2012.

[99] J. D. Veltman, M. E. H. Lambers, M. van Nimwegen et al., "Zoledronic acid impairs myeloid differentiation to tumourassociated macrophages in mesothelioma," British Journal of Cancer, vol. 103, no. 5, pp. 629-641, 2010.

[100] B. E. Houk, C. L. Bello, D. Kang, and M. Amantea, "A population pharmacokinetic meta-analysis of sunitinib malate (SU11248) and its primary metabolite (SU12662) in healthy volunteers and oncology patients," Clinical Cancer Research, vol. 15, no. 7, pp. 2497-2506, 2009.

[101] J. S. Ko, A. H. Zea, B. I. Rini et al., "Sunitinib mediates reversal of myeloid-derived suppressor cell accumulation in renal cell carcinoma patients," Clinical Cancer Research, vol. 15, no. 6, pp. 2148-2157, 2009.

[102] B. Schilling, A. Sucker, K. Griewank et al., "Vemurafenib reverses immunosuppression by myeloid derived suppressor cells," International Journal of Cancer, vol. 133, no. 7, pp. 16531663, 2013.

[103] L. Wu, C. Yan, M. Czader et al., "Inhibition of PPAR $\gamma$ in myeloid-lineage cells induces systemic inflammation, immunosuppression, and tumorigenesis," Blood, vol. 119, no. 1, pp. 115126, 2012.

[104] L. E. Sander, S. D. Sackett, U. Dierssen et al., "Hepatic acutephase proteins control innate immune responses during infection by promoting myeloid-derived suppressor cell function," Journal of Experimental Medicine, vol. 207, no. 7, pp. 1453-1464, 2010.

[105] J. Zhang, L. Patel, and K. J. Pienta, "CC chemokine ligand 2 (CCL2) promotes prostate cancer tumorigenesis and metastasis," Cytokine \& Growth Factor Reviews, vol. 21, no. 1, pp. 41-48, 2010.

[106] H. Qin, B. Lerman, I. Sakamaki et al., "Generation of a new therapeutic peptide that depletes myeloid-derived suppressor cells in tumor-bearing mice," Nature Medicine, vol. 20, no. 6, pp. 676-681, 2014.
[107] M. Fujita, G. Kohanbash, W. Fellows-Mayle et al., "COX2 blockade suppresses gliomagenesis by inhibiting myeloidderived suppressor cells," Cancer Research, vol. 71, no. 7, pp. 2664-2674, 2011.

[108] P. Serafini, K. Meckel, M. Kelso et al., "Phosphodiesterase5 inhibition augments endogenous antitumor immunity by reducing myeloid-derived suppressor cell function," The Journal of Experimental Medicine, vol. 203, no. 12, pp. 2691-2702, 2006.

[109] C. Meyera, A. Sevko, M. Ramacher et al., "Chronic inflammation promotes myeloid-derived suppressor cell activation blocking antitumor immunity in transgenic mouse melanoma model," Proceedings of the National Academy of Sciences of the United States of America, vol. 108, no. 41, pp. 17111-17116, 2011.

[110] V. Umansky and A. Sevko, "Overcoming immunosuppression in the melanoma microenvironment induced by chronic inflammation," Cancer Immunology, Immunotherapy, vol. 61, no. 2, pp. 275-282, 2012.

[111] S. Nagaraj, J.-I. Youn, H. Weber et al., "Anti-inflammatory triterpenoid blocks immune suppressive function of MDSCs and improves immune response in cancer," Clinical Cancer Research, vol. 16, no. 6, pp. 1812-1823, 2010.

[112] Y. Nefedova, M. Fishman, S. Sherman, X. Wang, A. A. Beg, and D. I. Gabrilovich, "Mechanism of all-trans retinoic acid effect on tumor-associated myeloid-derived suppressor cells," Cancer Research, vol. 67, no. 22, pp. 11021-11028, 2007.

[113] B. Almand, J. I. Clark, E. Nikitina et al., "Increased production of immature myeloid cells in cancer patients: a mechanism of immunosuppression in cancer," Journal of Immunology, vol. 166, no. 1, pp. 678-689, 2001.

[114] N. Mirza, M. Fishman, I. Fricke et al., "All-trans-retinoic acid improves differentiation of myeloid cells and immune response in cancer patients," Cancer Research, vol. 66, no. 18, pp. 92999307, 2006.

[115] T. Garrity, R. Pandit, M. A. Wright, J. Benefield, S. Keni, and M. R. I. Young, "Increased presence of $\mathrm{CD} 34^{+}$cells in the peripheral blood of head and neck cancer patients and their differentiation into dendritic cells," International Journal of Cancer, vol. 73, no. 5, pp. 663-669, 1997.

[116] D. M. R. Lathers, J. I. Clark, N. J. Achille, and M. R. I. Young, "Phase 1B study to improve immune responses in head and neck cancer patients using escalating doses of 25-hydroxyvitamin $\mathrm{D}_{3}$," Cancer Immunology, Immunotherapy, vol. 53, no. 5, pp. 422-430, 2004.

[117] M. Sade-Feldman, J. Kanterman, E. Ish-Shalom, M. Elnekave, E. Horwitz, and M. Baniyash, "Tumor necrosis factor-alpha blocks differentiation and enhances suppressive activity of immature myeloid cells during chronic inflammation," Immunity, vol. 38, no. 3, pp. 541-554, 2013.

[118] F. Shojaei, X. Wu, C. Zhong et al., "Bv8 regulates myeloid-celldependent tumour angiogenesis," Nature, vol. 450, no. 7171, pp. 825-831, 2007.

[119] J. Finke, J. Ko, B. Rini, P. Rayman, J. Ireland, and P. Cohen, "MDSC as a mechanism of tumor escape from sunitinib mediated anti-angiogenic therapy," International immunopharmacology, vol. 11, no. 7, pp. 856-861, 2011.

[120] S. Mabuchi, Y. Matsumoto, M. Kawano et al., "Uterine cervical cancer displaying tumor-related leukocytosis: a distinct clinical entity with radioresistant feature," Journal of the National Cancer Institute, vol. 106, no. 7, Article ID dju147, 2014.

[121] D. I. Gabrilovich, M. P. Velders, E. M. Sotomayor, and W. M. Kast, "Mechanism of immune dysfunction in cancer mediated 
by immature Gr-1 $1^{+}$myeloid cells," Journal of Immunology, vol. 166, no. 9, pp. 5398-5406, 2001.

[122] C. Iclozan, S. Antonia, A. Chiappori, D.-T. Chen, and D. Gabrilovich, "Therapeutic regulation of myeloid-derived suppressor cells and immune response to cancer vaccine in patients with extensive stage small cell lung cancer," Cancer Immunology, Immunotherapy, vol. 62, no. 5, pp. 909-918, 2013.

[123] H.-J. Ko, Y.-J. Kim, Y.-S. Kim et al., "A combination of chemoimmunotherapies can efficiently break self-tolerance and induce antitumor immunity in a tolerogenic murine tumor model," Cancer Research, vol. 67, no. 15, pp. 7477-7486, 2007.

[124] R. D'Amico, L. Lei, B. C. Kennedy et al., "The addition of Sunitinib to radiation delays tumor growth in a murine model of glioblastoma," Neurological Research, vol. 34, no. 3, pp. 252261, 2012.

[125] G. J. Freeman, A. J. Long, Y. Iwai et al., "Engagement of the PD-1 immunoinhibitory receptor by a novel B7 family member leads to negative regulation of lymphocyte activation," The Journal of Experimental Medicine, vol. 192, no. 7, pp. 1027-1034, 2000.

[126] S. L. Highfill, Y. Cui, A. J. Giles et al., "Disruption of CXCR2mediated MDSC tumor trafficking enhances anti-PD1 efficacy," Science Translational Medicine, vol. 6, no. 237, Article ID 237ra67, 2014.

[127] D. Chandra and C. Gravekamp, "Myeloid-derived suppressor cells: cellular missiles to target tumors," OncoImmunology, vol. 2, no. 11, Article ID e26967, 2013.

[128] L. Y. OuYang, X. J. Wu, S. B. Ye et al., "Tumor-induced myeloidderived suppressor cells promote tumor progression through oxidative metabolism in human colorectal cancer," Journal of Translational Medicine, vol. 13, article 47, 2015.

[129] T. Schneider, A. Sevko, C. Heussel et al., "Serum inflammatory factors and circulating immunosuppressive cells are predictive markers for efficacy of radiofrequency ablation in non-small cell lung cancer," Clinical \& Experimental Immunology, pp. n/a-n/a, 2015. 


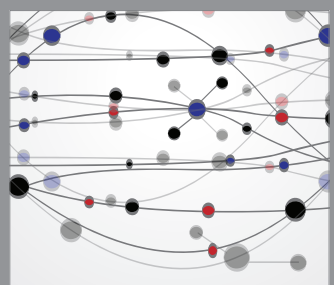

The Scientific World Journal
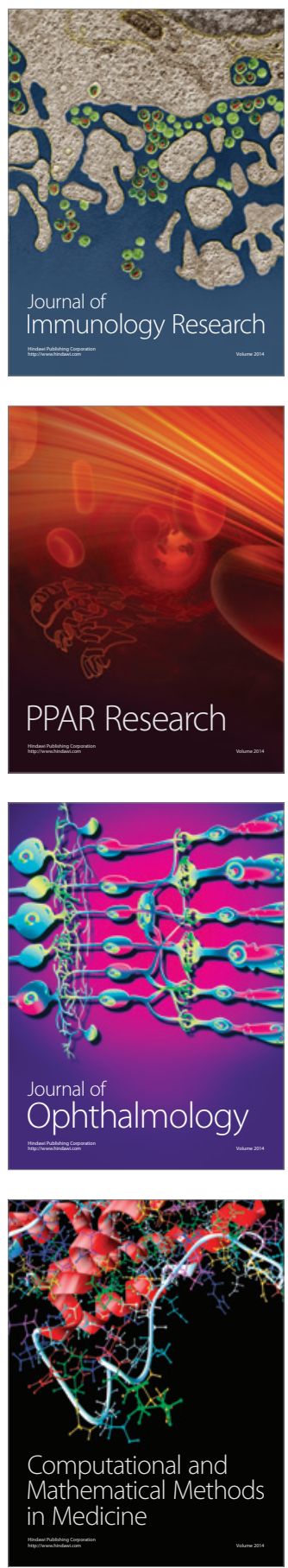

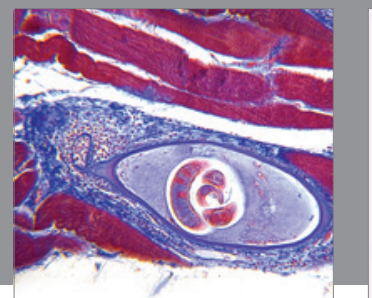

Gastroenterology

Research and Practice
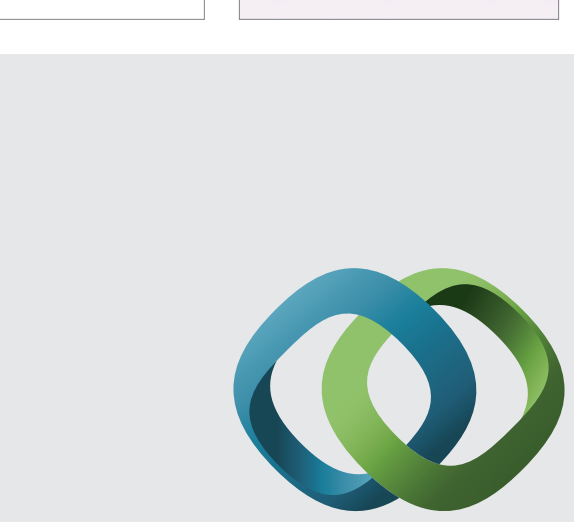

\section{Hindawi}

Submit your manuscripts at

http://www.hindawi.com
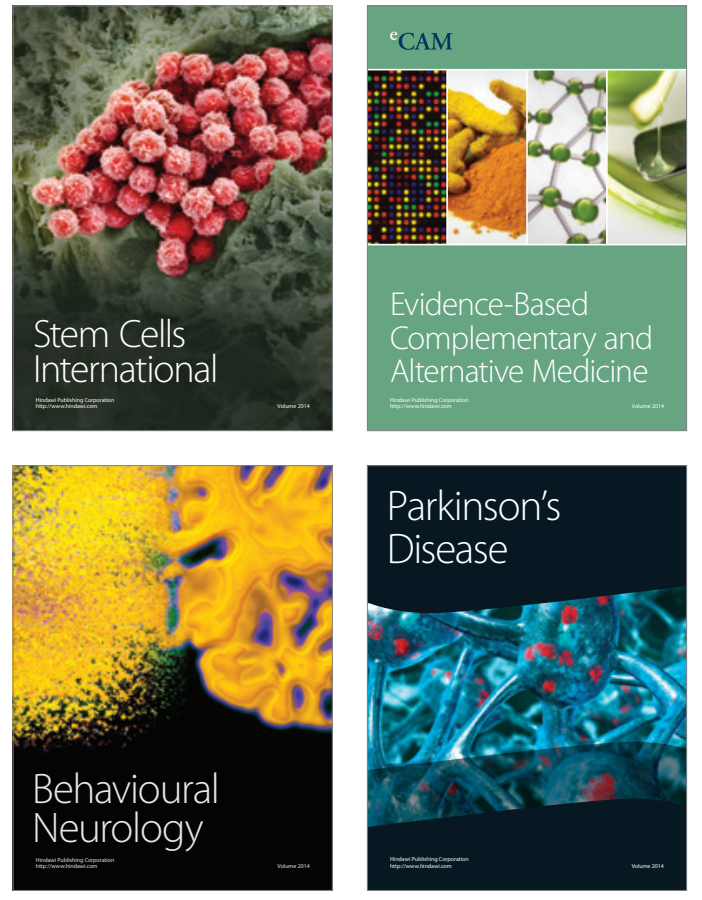
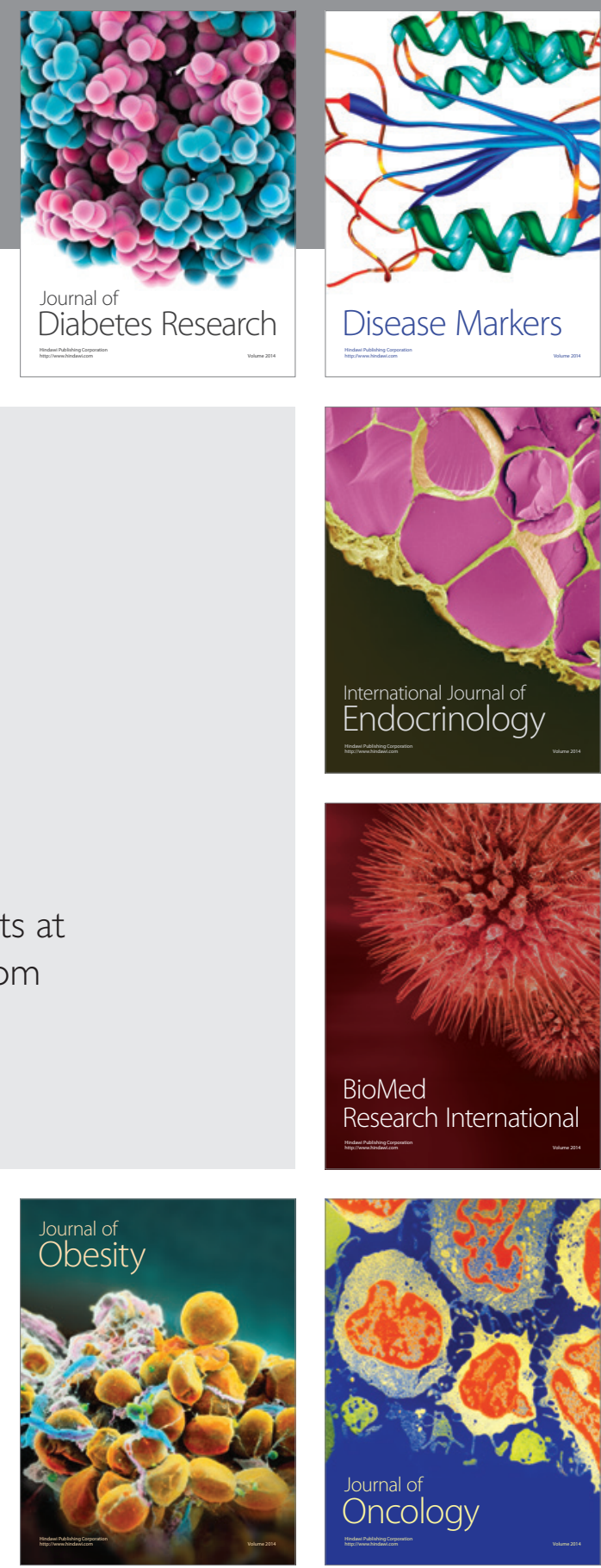

Disease Markers
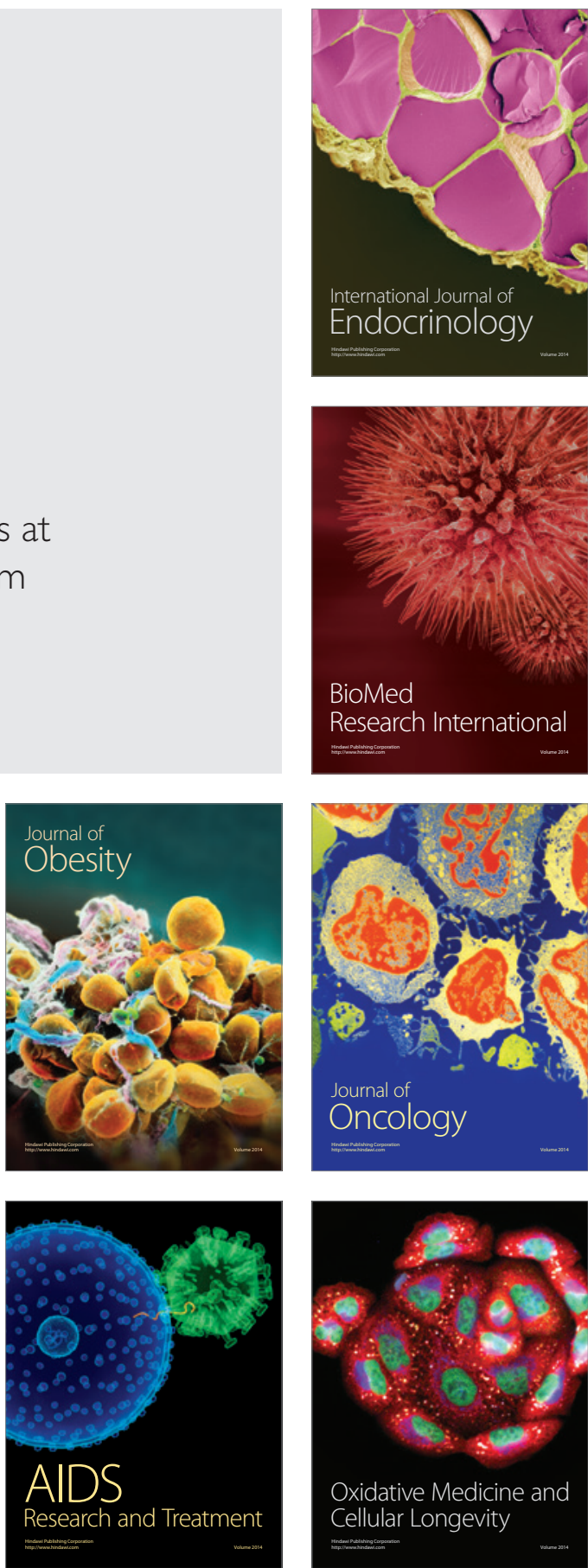